\title{
A New Hybrid MCDM Model for Personnel Selection Based on a Novel Grey PIPRECIA and Grey OCRA Methods
}

\author{
Alptekin Ulutaş ${ }^{1}{ }^{(}$, Gabrijela Popovic $^{2}{ }^{(0)}$, Dragisa Stanujkic ${ }^{3}\left(\mathbb{D}\right.$, Darjan Karabasevic ${ }^{2, *} * \mathbb{C}$, \\ Edmundas Kazimieras Zavadskas ${ }^{4}$ (D) and Zenonas Turskis ${ }^{4}$ (D) \\ 1 Department of International Trade and Logistics, Faculty of Economics and Administrative Sciences, \\ Sivas Cumhuriyet University, Sivas 58140, Turkey; aulutas@cumhuriyet.edu.tr \\ 2 Faculty of Applied Management, Economics and Finance, University Business Academy in Novi Sad, \\ Belgrade, Serbia, Jevrejska 24, 11000 Belgrade, Serbia; gabrijela.popovic@mef.edu.rs \\ 3 Technical Faculty in Bor, University of Belgrade, Vojske Jugoslavije 12, 19210 Bor, Serbia; \\ dstanujkic@tfbor.bg.ac.rs \\ 4 Institute of Sustainable Construction, Vilnius Gediminas Technical University, LT 10223 Vilnius, Lithuania; \\ Edmundas.Zavadskas@vgtu.lt (E.K.Z.); zenonas.turskis@vgtu.lt (Z.T.) \\ * Correspondence: darjan.karabasevic@mef.edu.rs or darjankarabasevic@gmail.com
}

Received: 18 September 2020; Accepted: 27 September 2020; Published: 3 October 2020

\begin{abstract}
People represent one of the most significant resources of an organization, and therefore, personnel selection is one of the problems that organizations have increasingly been facing. The criteria that influence the final decision are usually opposing, so the application of multiple-criteria decision-making methods (MCDM) represents a suitable way for the facilitation of the given process. Additionally, the decision environment is characterized by the vagueness and uncertainty and, because of that, it is very hard to express the criteria over the exact crisp numbers. To acknowledge the unpredictability and obscurity of the available information important for the selection of the optimal candidate, a hybrid grey MCDM model for personnel selection is proposed in this paper. As an extension of the PIPRECIA method, the novel Grey Pivot Pairwise Relative Criteria Importance Assessment-the PIPRECIA-G method-is proposed and used for the determination of criteria importance. The PIPRECIA-G method preserved the good features of the PIPRECIA, but its superiority is reflected in its ability to deal with input data that are vague and grey. For the final ranking of the considered alternative candidates, the OCRA-G method is used. Basing the decision process and candidate selection on the two grey extended MCDM methods contributes to the increase of the reliability and confidence in the performed selection.
\end{abstract}

Keywords: personnel selection; PIPRECIA-G; OCRA-G; MCDM

\section{Introduction}

In years to come, attracting, selecting, and retaining high-quality and competent personnel will be one of the most challenging management issues. Managers and professionals in the human resources sector need to have a strategy in place to deal with these issues. Managers who need to decide on the selection and recruitment of new personnel must eliminate subjectivity and must promulgate their decisions objectively in that process and decide on the selection of quality and competent candidates [1].

The selection of an adequate employee for a particular position in an organization requires a careful estimation and assessment of his/her performances. For that purpose, appropriate selection systems involving a certain number of evaluation criteria have been developed. These systems are often based on the application of various types of tests, such as: integrity tests, short-term 
memory tests, situational judgment tests, and other types [2-4]. Additionally, including personality measures into the personnel selection process is becoming a common practice [5]. Nowadays, modern technologies are introducing new ways of recruiting and selecting personnel through social networking sites. The common denominator of the personnel selection process, however, is undoubtedly the existence of an appropriate set of perspectives or criteria, which form the basis for conducting the evaluation procedure.

To acknowledge all evaluation criteria during the selection process and avoid biased decisions and choices is certainly not an easy assignment for a manager, i.e., decision-maker (from now on referred to as DM), to do. One helpful tool that could increase the reliability of the performed selection and decrease the subjectivity of the choices made is certainly represented by Multiple-Criteria Decision-Making (MCDM) methods. These methods have been used to facilitate the decision-making process in many business fields, having recently gained popularity in the field of personnel selection, as well [6-11].

The traditional MCDM methods are designed for using crisp data that ambiguously outline the value of the involved criteria. In this way, the decision process is certainly facilitated, but the final results could be somewhat unreliable. The reason for the questionable reliability of the obtained results lies in the inability of the crisp data to represent the considered criteria in the proper way. It is very hard, even impossible, to define such a set of criteria that could be designated as crisp values without undermining their actuality. This is true for the problem of employee selection, as well. Besides the fact that the criteria relative to candidates are mainly of the qualitative nature, it is very difficult to express the criteria related to the candidate's competencies in the form of unique values. With the goal of overcoming the problem of deficient expression of the input values, the authors have introduced different extensions of the MCDM methods based on the fuzzy, grey or neutrosophic numbers. For the purpose of this paper, the proposed extension is contrived on the application of grey numbers.

The Grey Pivot Pairwise Relative Criteria Importance Assessment-PIPRECIA-G-is first introduced as an extension of the PIPRECIA method to be used to determine the criteria importance. Although the PIPRECIA method represents a suitable and straightforward technique for defining the criteria importance, it is not designed to appreciate the vagueness of the decision environment to a satisfying degree. Because of overcoming the mentioned deficiency, the grey extension of the PIPRECIA method is developed in this paper. Then, the final evaluation and selection of the employees for a particular work position in a textile factory are carried out using the Grey Operational Competitiveness Rating (OCRA-G) method. The given approach enables the final evaluation and ranking of the alternative candidates to be performed by acknowledging estimated lower and higher values connected to the candidates' performances. Finally, the authors' main intention is to emphasize the advantages of the proposed methods, which for their part are easy, understandable, and appropriate to apply in the case of personnel selection in an uncertain and vague environment, because they facilitate the decision-making process and increase the reliability of the choices made. With that aim, the remainder of the paper is organized as follows: the second part of the paper contains a comprehensive literature review; in the third part, the methodology to be used is presented; in the fourth part of the paper, the application of the proposed methodology is elaborated in a real case study; ultimately, the final conclusion is given.

\section{Literature Review}

So far, a lot of personnel assessment and selection techniques have been proposed, with one uniform goal-to ensure the quality and rightness of the choice of an employee for a certain position. It is very important to select an appropriate unbiased evaluation procedure that is valid and reliable at the same time [12]. This is a very important issue, as the evaluation procedures that potential employees go through have an influence on them, too [13].

Before commencing the personnel selection process, it is necessary that criteria should be defined, against which criteria alternative candidates will be assessed and ranked. So far, different authors 
have proposed different sets of criteria for that matter. For example, Kelemenis and Askounis [14], based on the selection of a CIO for an IT firm, proposed eleven criteria that are roughly divided into "soft" skills and technical skills. In the case of personnel selection, Baležentis et al. [15] used a total of eight criteria and linguistic variables relying on a 7-point scale. For the purpose of hiring a project manager, Afshari et al. [16] introduced four groups of criteria, inclusive of a certain number of sub-criteria, into the evaluation process. However, regardless of the number of the criteria involved in the decision-making process, the determination of their significance is an obligatory step in the application of each MCDM method. Different MCDM techniques suitable for the identification of criteria significance have been introduced to date. To mention only a few of them: the Analytic Hierarchy Process-AHP [17], the Entropy method [18], KEmeny Median Indicator Ranks Accordance-KEMIRA [19] and KEMIRA-M [20], and Stepwise Weight Assessment Ratio Analysis-SWARA [21]. For the needs of this paper, we developed Grey PIvot Pairwise RElative Criteria Importance Assessment-PIPRECIA-G—which is based on the PIPRECIA method introduced by Stanujkic et al. [22].

The PIPRECIA method developed by Stanujkic et al. [22] represents an improved version of the SWARA method, which was proposed earlier by Keršuliene et al. [21]. Very briefly, the SWARA method has gained particular popularity among researchers in cases where the determination of criterion significance is involved, because of its simplicity and intelligibility, as proven by a lot of research studies [23-27]. Apart from the mentioned good features of the SWARA method, it also has certain deficiencies. The main shortcoming of the SWARA method is the obligatory ranking of criteria according to their considered significances, which complicates its application in a group decision-making environment. Additionally, contrary to the well-known and widely used AHP method, SWARA does not predict consistency testing, so the obtained results can be unreliable to some extent. Stanujkic et al. [22] recognized these issues and proposed the PIPRECIA method, which is an upgraded SWARA method. The PIPRECIA method is used to facilitate the decision-making process in many real-world problems, such as the evaluation of the quality of websites [28], the estimation of the importance of sustainable indicators for cultural heritage sites [29], the appraisal of projects in the tourism field [30], the defining of customer satisfaction in Serbian restaurants [31], and the ranking of e-commerce development strategies [32]. The fuzzy extension of the PIPRECIA method was recently proposed by Stević et al. [33], and its applicability was demonstrated in a case study dedicated to the selection of information technology for the warehouse system. In the present study, PIPRECIA-G is proposed as a suitable tool for the determination of the criteria significance in this particular case.

When the final ranking and selection of candidates is in question, in recent research studies, authors have proposed the application of MCDM techniques as a useful tool that leads to justified choices. The decision-making process in the field of human resources management could be facilitated by using the TOPSIS method [14]. Afshari et al. [34] proposed the application of the simple additive weighted method to solve a personnel selection problem. Stanujkic et al. [35] suggested the adapted weighted sum and SWARA methods, whereas Karabasevic et al. [36] introduced the EDAS method as a decision aid in the same field. The combination of the SWARA and the WASPAS methods could also be a very convenient tool for the selection of an appropriate employee [37].

To acknowledge the uncertainty and vagueness of the environment, many authors have proposed the application of extended MCDM methods. For example, Baležentis et al. [15] proposed the application of fuzzy MULTIMOORA, whereas Kabak et al. [38] introduced a fuzzy multiple-criteria approach based on the ANP, TOPSIS and ELECTRE methods. In a paper by Liu et al. [39], a framework including the VIKOR method combined with interval 2-tuple linguistic variables was proposed. Sang et al. [40] suggested the improved fuzzy TOPSIS method based on an analytical solution. Intending to develop the approach that will enable the selection of the best candidate by respecting all considered criteria, Karabasevic et al. [41] used the SWARA and ARAS methods in combination with fuzzy numbers. Ji et al. [42] suggested the application of the projection-based TODIM method, which implies the introduction of multi-valued neutrosophic sets, whereas Heidary Dahooie et al. [43] used the hybrid 
SWARA and grey ARAS frameworks. In this paper, the application of OCRA-G as a technique suitable for the facilitation of the decision-making process in the case of personnel selection is proposed.

The OCRA method was proposed by Parkan [44] and has been further improved by Parkan and $\mathrm{Wu}$ [45]. In his paper, Wang [46] made comments about the applicability of the OCRA method, expressing the attitude that the OCRA method had certain flaws. Despite this, the OCRA method has been used to facilitate the decision-making process in several fields. A material selection problem was the subject matter of the application of this technique [47]. Özbek [48] conducted an efficiency analysis of banks in Turkey by using the OCRA and MOORA methods. Işık and Adalı [49] used it in combination with the SWARA method to solve a hotel selection problem. In the paper by Madic et al. [50], the stability of the obtained results is checked by using the mentioned method. Stanujkic et al. [51] proposed an improvement of the OCRA technique based on interval grey numbers. No evidence has been furnished so far of the application of the OCRA method in the field of personnel selection. This fact leads to the conclusion that there is room for testing the possibilities of OCRA, as well as the OCRA-G method, in human resources management and in other business and scientific fields, too.

\section{Methodology}

In this study, the new extension of the PIPRECIA-G (Grey Pivot Pairwise Relative Criteria Importance Assessment) and the OCRA-G methods are used to address a personnel selection problem. PIPRECIA-G is used to determine the weights of the criteria, whereas the OCRA-G method is used to rank alternatives, i.e., in our case personnel.

\subsection{The PIPRECIA-G Method}

The superiority of the PIPRECIA-G method to the grey SWARA method is the fact that it allows for the evaluation of criteria without prioritizing by importance. Especially in group decision-making problems, the PIPRECIA-G method is superior to the grey SWARA method due to this feature. The PIPRECIA-G method consists of 10 steps.

Step 1: A set of criteria is defined, and an expert team is formed. The criteria are sorted from the first to the last, with respect to marks. However, their importance does not play any role in this step.

Step 2: The relative significance of the criteria is identified. In this step, starting from the second criterion, each expert assesses the pre-sorted criteria individually.

$$
\otimes e_{j}^{r}= \begin{cases}>\otimes 1 & \text { if } C_{j}>C_{j-1} \\ =\otimes 1 & \text { if } C_{j}=C_{j-1} \\ <\otimes 1 & \text { if } C_{j}<C_{j-1}\end{cases}
$$

In Equation (1), $\otimes e_{j}^{r}$ is the evaluation of the $j$ th criterion made by the expert $r$. When determining this value, experts will use Table 1 (if $C_{j}<C_{j-1}$ ) and Table 2 (if $C_{j}>C_{j-1}$ ). Then, the individual values are combined by the geometric mean.

Table 1. The 0-1 scale for the evaluation of the criteria (adapted from Stević et al. [33]).

\begin{tabular}{ccc}
\hline & \multicolumn{2}{c}{ Grey Values } \\
\cline { 2 - 3 } Linguistic Values & $\underline{\boldsymbol{e}}_{j}$ & $\overline{\boldsymbol{e}}_{j}$ \\
\hline Absolutely less important & 0.236 & 0.268 \\
Dominantly less important & 0.268 & 0.310 \\
Much less important & 0.310 & 0.367 \\
Really less important & 0.367 & 0.450 \\
Less important & 0.450 & 0.584 \\
Moderately less important & 0.584 & 0.834 \\
Weakly less important & 0.834 & 1 \\
\hline
\end{tabular}


Table 2. The 1-2 scale for the evaluation of the criteria (adapted from Stević et al. [33]).

\begin{tabular}{ccc}
\hline & \multicolumn{2}{c}{ Grey Values } \\
\cline { 2 - 3 } Linguistic Values & $\underline{e}_{j}$ & $\overline{\boldsymbol{e}}_{j}$ \\
\hline Absolutely more important & 1.750 & 1.925 \\
Dominantly more important & 1.625 & 1.775 \\
Much more important & 1.500 & 1.625 \\
More important & 1.375 & 1.475 \\
Moderately more important & 1.250 & 1.325 \\
Slightly more important & 1.125 & 1.175 \\
Almost equal value & 1 & 1 \\
\hline
\end{tabular}

Step 3: If $j=1, \otimes k_{j}=\left[k_{j}, \bar{k}_{j}\right]$ coefficient equals $\otimes 1$. If $j>1, \otimes k_{j}=\left[k_{j}, \bar{k}_{j}\right]$ coefficient is computed as follows:

$$
\otimes k_{j}=\left[k_{j}, \bar{k}_{j}\right]=2-\otimes e_{j}=\left[\left(2-\bar{e}_{j}\right),\left(2-e_{j}\right)\right]
$$

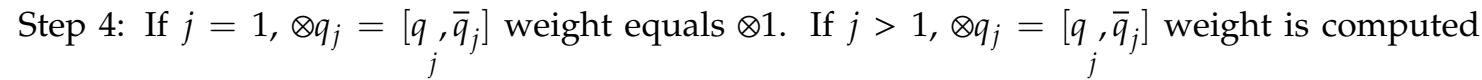
as follows:

$$
\otimes q_{j}=\left[\begin{array}{c}
q, \bar{q}_{j} \\
j
\end{array}\right]=\frac{\otimes q_{j-1}}{\otimes k_{j}}=\left[(\underbrace{q}_{j-1} \bar{k}_{j}),\left(\frac{\bar{q}_{j-1}}{k_{j}}\right)\right]
$$

Step 5: A grey relative weight $\left(\otimes w_{j}\right)$ for each criterion is computed as follows:

$$
\otimes w_{j}=\left[w_{j}, \bar{w}_{j}\right]=\frac{\otimes q_{j}}{\sum_{j=1}^{n} \otimes q_{j}}=\left[\frac{{ }_{j}}{\sum_{j=1}^{n} \bar{q}_{j}}, \frac{\bar{q}_{j}}{\sum_{j=1}^{n} q_{j}}\right]
$$

In Equation (4), $n$ indicates the total number of the criteria.

Step 6: The inverse technique of the PIPRECIA-G method is indicated in the following steps. The above-mentioned steps will be repeated. This time, however, the process starts from the penultimate criterion.

$$
\otimes e_{j}^{r^{\prime}}=\left\{\begin{array}{l}
>\otimes 1 \text { if } C_{j}>C_{j+1} \\
=\otimes 1 \text { if } C_{j}=C_{j+1} \\
<\otimes 1 \text { if } C_{j}<C_{j+1}
\end{array}\right.
$$

In Equation (1), $\otimes e_{j}^{r^{\prime}}$ is the evaluation of the $j$ th criterion made by the expert $r$.

Step 7: If $j=n, \otimes k_{j}^{\prime}=\left[k_{j}^{\prime}, \bar{k}_{j}^{\prime}\right]$ coefficient equals $\otimes 1$. If $j>n, \otimes k_{j}^{\prime}=\left[k_{j}^{\prime}, \bar{k}_{j}^{\prime}\right]$ coefficient is computed as follows:

$$
\otimes k_{j}^{\prime}=\left[k_{j}^{\prime}, \bar{k}_{j}^{\prime}\right]=2-\otimes e_{j}^{\prime}=\left[\left(2-\bar{e}_{j}^{\prime}\right),\left(2-e_{j}^{\prime}\right)\right]
$$

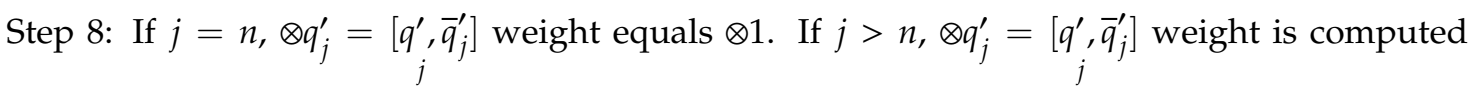
as follows:

$$
\otimes q_{j}^{\prime}=\left[q_{j}^{\prime}, \bar{q}_{j}^{\prime}\right]=\frac{\otimes q_{j-1}^{\prime}}{\otimes k_{j}^{\prime}}=\left[\left(\begin{array}{c}
q_{j-1}^{\prime} \\
\bar{k}_{j}^{\prime}
\end{array}\right),\left(\frac{\bar{q}_{j-1}^{\prime}}{k_{j}^{\prime}}\right)\right]
$$


Step 9: A grey relative weight $\left(\otimes w_{j}^{\prime}\right)$ for each criterion is computed as follows:

$$
\otimes w_{j}^{\prime}=\left[w_{j}^{\prime}, \bar{w}_{j}^{\prime}\right]=\frac{\otimes q_{j}^{\prime}}{\sum_{j=1}^{n} \otimes q_{j}^{\prime}}=\left[\frac{q_{j}^{\prime}}{\sum_{j=1}^{n} \bar{q}_{j}^{\prime}}, \frac{\bar{q}_{j}^{\prime}}{\sum_{j=1}^{n} q_{j}^{\prime}}\right]
$$

Step 10: The final grey weight $\left(\otimes w_{j}^{\prime \prime}=\left[w_{j}^{\prime \prime}, \bar{w}_{j}^{\prime \prime}\right]\right)$ for each criterion is computed by using Equation (9), namely in the following manner:

$$
\otimes w_{j}^{\prime \prime}=\left[w_{j}^{\prime \prime}, \bar{w}_{j}^{\prime \prime}\right]=\frac{\otimes w_{j}^{\prime}+\otimes w_{j}}{2}=\left[\frac{w_{j}^{\prime}+w_{j}}{2}, \frac{\bar{w}_{j}^{\prime}+\bar{w}_{j}}{2}\right]
$$

\subsection{The OCRA-G Method}

The final grey weights are transferred by OCRA-G method. In this study, the OCRA-G method is used to rank the personnel alternatives. The steps of OCRA-G are summarized as follows [51]:

Step 1. Experts assign a performance rating to each personnel alternative in order to form a grey decision matrix $(\otimes F)$. When assigning these ratings, experts use the linguistic values indicated in Table 3.

$$
\otimes F=\left[\begin{array}{cccc}
\otimes f_{11} & \otimes f_{12} & \ldots & \otimes f_{1 n} \\
\otimes f_{21} & \otimes f_{22} & \ldots & \otimes f_{2 n} \\
\vdots & \vdots & \ldots & \vdots \\
\otimes f_{m 1} & \otimes f_{m 2} & \ldots & \otimes f_{m n}
\end{array}\right]
$$

Table 3. The linguistic and grey values for performance rating [52].

\begin{tabular}{ccc}
\hline & \multicolumn{2}{c}{ Grey Values } \\
\cline { 2 - 3 } Linguistic Values & $f$ & - \\
& ${ }^{i j}$ & $f_{i j}$ \\
\hline Very high & 0.800 & 1 \\
High & 0.700 & 0.900 \\
Medium high & 0.600 & 0.800 \\
Medium & 0.350 & 0.650 \\
Medium low & 0.200 & 0.400 \\
Low & 0.100 & 0.300 \\
Very low & 0 & 0.200 \\
\hline
\end{tabular}

$\otimes f_{i j}(\in \otimes F)=\left[f_{i j}, \bar{f}_{i j}\right]$ denotes the performance rating of the $i$ th alternative on the $j$ th criterion.

Step 2. For non-beneficial criteria, grey aggregate performance ratings $\left(\otimes I_{i}=\left[I_{i} \bar{I}_{i}\right]\right)$ are computed as follows:

$$
\otimes I_{i}=\sum_{j \in \Omega_{\min }} \otimes w_{j}^{\prime \prime} \frac{\max _{j} \otimes f_{i j}-\otimes f_{i j}}{\max _{j} \otimes f_{i j}-\min _{j} \otimes f_{i j}}
$$

By using the basic grey arithmetic operations, Equation (11) can be written down in detail as presented below:

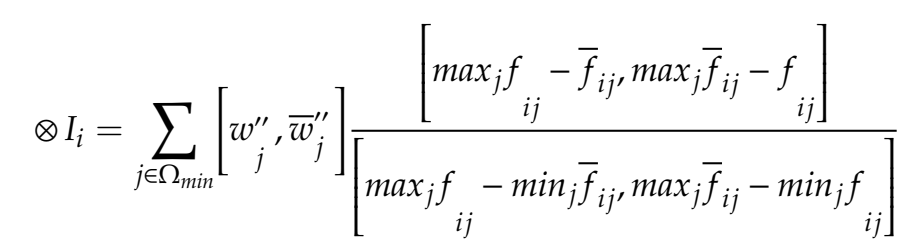


Step 3. For non-beneficial criteria, grey linear performance ratings $\left(\otimes S_{i}=\left[S_{i}, \bar{S}_{i}\right]\right)$ are calculated as follows:

$$
\otimes S_{i}=\otimes I_{i}-\min _{i} \otimes I_{i}=\left[I_{i}-\min _{i} \bar{I}_{i}, \bar{I}_{i}-\min _{i} I_{i}\right]
$$

Step 4. For beneficial criteria, grey aggregate performance ratings $\left(\otimes O_{i}=\left[O_{i} \bar{O}_{i}\right]\right)$ are calculated as follows:

$$
\otimes O_{i}=\sum_{j \in \Omega_{\max }} \otimes w_{j}^{\prime \prime} \frac{\otimes f_{i j}-\min _{j} \otimes f_{i j}}{\max _{j} \otimes f_{i j}-\min _{j} \otimes f_{i j}}
$$

Equations (14) and (15) can be written down in detail as presented below:

$$
\otimes O_{i}=\sum_{j \in \Omega_{\max }}\left[w_{j}^{\prime \prime}, \bar{w}_{j}^{\prime \prime}\right] \frac{\left[f_{i j}-\min _{j} \bar{f}_{i j}, \bar{f}_{i j}-\min _{j} f{ }_{i j}\right]}{\left[\max _{j} f_{i j}-\min _{j} \bar{f}_{i j}, \max _{j} \bar{f}_{i j}-\min _{j} f_{i j}\right]}
$$

Step 5. For beneficial criteria, grey linear performance ratings $\left(\otimes R_{i}=\left[R_{i}, \bar{R}_{i}\right]\right)$ are calculated as follows:

$$
\otimes R_{i}=\otimes O_{i}-\min _{i} \otimes O_{i}=\left[O_{i}-\min _{i} \bar{O}_{i}, \bar{O}_{i}-\min _{i} O{ }_{i}\right]
$$

Step 6. The final grey score for each alternative $\left(\otimes P_{i}=\left[P_{i}, \bar{P}_{i}\right]\right)$ is computed in the following manner:

$$
\otimes P_{i}=\otimes S_{i}+\otimes R_{i}-\min _{i}\left(\otimes S_{i}+\otimes R_{i}\right)
$$

Equation (17) can be written down in detail as presented below.

$$
\otimes P_{i}=\left[P_{i}, \bar{P}_{i}\right]=\left[S_{i}+R_{i}-\min _{i}\left(\bar{S}_{i}+\bar{R}_{i}\right), \bar{S}_{i}+\bar{R}_{i}-\min _{i}\left(S_{i}+R_{i}\right)\right]
$$

Step 7. The final grey scores $\left(\otimes P_{i}=\left[P_{i}{ }_{i} \bar{P}_{i}\right]\right)$ are converted into the final crisp $\left(P_{i}\right)$ scores by using Equation (19).

$$
P_{i}=\frac{P_{i}+\bar{P}_{i}}{2}
$$

The alternatives are ranked from the highest to the lowest score.

\section{A Case Study}

A textile factory with more than 500 employees would like to employ a manager in charge of production. A team of experts, including the factory manager, the assistant manager, and the human resource manager, was formed for the purpose of the personnel evaluation and selection. The expert team were asked to determine the criteria to be used in the selection of the personnel by using the criteria previously used in the literature or identifying such criteria by themselves. The team determined the criteria that would be used in the assessment. The criteria are indicated below:

- The knowledge of a product, a raw material and manufacturing (KPRM);

- Experience in the textile manufacturing sector (ETM);

- Teamwork compatibility (TC);

- $\quad$ Risk assessment skills (RAS);

- $\quad$ A requested wage $(\mathrm{RW})$;

- The awareness of technological developments in the sector (ATD);

- The knowledge of the computer programs used in the sector (KCP). 
The expert team evaluated the above criteria individually. To combine individual assessments, the geometric mean was used. The assessments for PIPRECIA-G and inverse PIPRECIA-G are indicated in Tables 4 and 5, respectively.

Table 4. The assessment for PIPRECIA-G.

\begin{tabular}{ccccc}
\hline Criteria & Experts & Expert 2 & Expert 3 & Geometric Mean \\
\cline { 1 - 5 } KPRM & & & & \\
\hline KCP & {$[0.834,1]$} & {$[0.834,1]$} & {$[0.834,1]$} & {$[0.834,1]$} \\
\hline RAS & {$[0.367,0.450]$} & {$[0.367,0.450]$} & {$[0.236,0.268]$} & {$[0.317,0.379]$} \\
\hline RW & {$[0.450,0.584]$} & {$[0.584,0.834]$} & {$[1.625,1.775]$} & {$[0.753,0.953]$} \\
\hline TC & {$[0.367,0.450]$} & {$[0.450,0.584]$} & {$[0.584,0.834]$} & {$[0.459,0.603]$} \\
\hline EM & {$[0.584,0.834]$} & {$[1.625,1.775]$} & {$[0.584,0.834]$} & {$[0.821,1.073]$} \\
\hline ATD & {$[0.584,0.834]$} & {$[0.236,0.268]$} & {$[0.584,0.834]$} & {$[0.432,0.571]$} \\
\hline
\end{tabular}

Table 5. The assessment for inverse PIPRECIA-G.

\begin{tabular}{ccccc}
\hline Experts & \multirow{2}{*}{ Expert 1 } & Expert 2 & Expert 3 & Geometric Mean \\
\hline ATD & & & & \\
\hline EM & {$[1.125,1.175]$} & {$[1.125,1.175]$} & {$[1.250,1.325]$} & {$[1.165,1.223]$} \\
\hline TC & {$[1.125,1.175]$} & {$[0.310,0.367]$} & {$[1.375,1.475]$} & {$[0.783,0.860]$} \\
\hline RW & {$[1.250,1.325]$} & {$[1.125,1.175]$} & {$[0.450,0.584]$} & {$[0.859,0.969]$} \\
\hline RAS & {$[1.250,1.325]$} & {$[1.125,1.175]$} & {$[1.250,1.325]$} & {$[1.207,1.273]$} \\
\hline KP & {$[1.375,1.475]$} & {$[1.125,1.175]$} & {$[1.250,1.325]$} & {$[1.246,1.319]$} \\
\hline KPRM & {$[1.625,1.775]$} & {$[1.375,1.475]$} & {$[1.250,1.325]$} & {$[1.408,1.514]$} \\
\hline
\end{tabular}

Using Equations (2)-(4), the results of PIPRECIA-G were obtained. These results are shown in Table 6.

Table 6. The results of PIPRECIA-G.

\begin{tabular}{|c|c|c|c|c|}
\hline Criteria & $\otimes e_{j}$ & $\otimes \boldsymbol{k}_{j}$ & $\otimes \boldsymbol{q}_{j}$ & $\otimes w_{j}$ \\
\hline KPRM & & {$[1,1]$} & {$[1,1]$} & {$[0.227,0.293]$} \\
\hline $\mathrm{KCP}$ & {$[0.834,1]$} & {$[1,1.166]$} & {$[0.858,1]$} & {$[0.195,0.293]$} \\
\hline RAS & {$[0.317,0.379]$} & {$[1.621,1.683]$} & {$[0.510,0.617]$} & {$[0.116,0.181]$} \\
\hline RW & {$[0.753,0.953]$} & {$[1.047,1.247]$} & {$[0.409,0.589]$} & {$[0.093,0.173]$} \\
\hline TC & {$[0.459,0.603]$} & {$[1.397,1.541]$} & {$[0.265,0.422]$} & {$[0.060,0.124]$} \\
\hline EM & {$[0.821,1.073]$} & {$[0.927,1.179]$} & {$[0.225,0.455]$} & {$[0.051,0.133]$} \\
\hline ATD & {$[0.432,0.571]$} & {$[1.429,1.568]$} & {$[0.143,0.318]$} & {$[0.032,0.093]$} \\
\hline
\end{tabular}

Using Equations (6)-(8), the results of inverse PIPRECIA-G were computed. These results are shown in Table 7. 
Table 7. The results of inverse PIPRECIA-G.

\begin{tabular}{ccccc}
\hline Criteria & \multirow{2}{*}{ Results } & \multirow{2}{*}{$\boldsymbol{e}_{j}^{\prime}$} & \multirow{2}{*}{$\boldsymbol{k}_{j}^{\prime}$} & $\otimes \boldsymbol{q}_{j}^{\prime}$ \\
\hline ATD & & {$[1,1]$} & {$[1,1]$} & {$[0.078,0.111]$} \\
\hline EM & {$[1.165,1.223]$} & {$[0.777,0.835]$} & {$[1.198,1.287]$} & {$[0.094,0.143]$} \\
\hline TC & {$[0.783,0.860]$} & {$[1.140,1.217]$} & {$[0.984,1.129]$} & {$[0.077,0.125]$} \\
\hline RW & {$[0.859,0.969]$} & {$[1.031,1.141]$} & {$[0.862,1.095]$} & {$[0.067,0.122]$} \\
\hline RAS & {$[1.207,1.273]$} & {$[0.727,0.793]$} & {$[1.087,1.506]$} & {$[0.085,0.167]$} \\
\hline KP & {$[1.246,1.319]$} & {$[0.681,0.754]$} & {$[1.442,2.211]$} & {$[0.113,0.245]$} \\
\hline KPRM & {$[1.408,1.514]$} & {$[0.486,0.592]$} & {$[2.436,4.549]$} & {$[0.191,0.505]$} \\
\hline
\end{tabular}

Using Equation (9), the final grey weights $\left(\otimes w_{j}^{\prime \prime}\right)$ of the criteria were computed. The final grey weights are presented in Table 8.

Table 8. The final grey weights.

\begin{tabular}{cc}
\hline Criteria $^{\text {Results }}$ & $\otimes w_{j}^{\prime \prime}$ \\
\hline KPRM & {$[0.209,0.399]$} \\
\hline KCP & {$[0.154,0.269]$} \\
\hline RAS & {$[0.101,0.174]$} \\
\hline RW & {$[0.080,0.148]$} \\
\hline TC & {$[0.069,0.125]$} \\
\hline EM & {$[0.073,0.138]$} \\
\hline ATD & {$[0.055,0.102]$} \\
\hline
\end{tabular}

After computing the final grey weights, the OCRA-G method was used to evaluate the personnel alternatives. There are eight people who applied for the job. A total of three out of the eight people were eliminated in the first stage since they did not have an adequate education level. The remaining five candidates were subjected to a one-week trial period at the factory. The expert team observed the candidates for a week, demanding from the candidates an activity report on a daily basis. In addition, the candidates were asked what amount of the wage (euros) they requested. Thus, the expert team evaluated the candidates jointly with respect to the observation results and the reports received from the candidates. The grey decision matrix containing the evaluations of the expert team is shown in Table 9. 
Table 9. The grey decision matrix.

\begin{tabular}{|c|c|c|c|c|}
\hline Alternatives & $\mathbf{K P}$ & RAS & TC & EM \\
\hline Candidate 1 & {$[0.350,0.650]$} & {$[0.350,0.650]$} & {$[0.350,0.650]$} & {$[0.600,0.800]$} \\
\hline Candidate 2 & {$[0.200,0.400]$} & {$[0.200,0.400]$} & {$[0.600,0.800]$} & {$[0.350,0.650]$} \\
\hline Candidate 3 & {$[0.350,0.650]$} & {$[0.600,0.800]$} & {$[0.600,0.800]$} & {$[0.600,0.800]$} \\
\hline Candidate 4 & {$[0.600,0.800]$} & {$[0.200,0.400]$} & {$[0.350,0.650]$} & {$[0.350,0.650]$} \\
\hline Candidate 5 & {$[0.350,0.650]$} & {$[0.200,0.400]$} & {$[0.200,0.400]$} & {$[0.200,0.400]$} \\
\hline Alternatives & ATD & \multicolumn{2}{|c|}{ RW } & KPRM \\
\hline Candidate 1 & {$[0.350,0.650]$} & \multicolumn{2}{|c|}{$[1000,1200]$} & {$[0.600,0.800]$} \\
\hline Candidate 2 & {$[0.600,0.800]$} & \multicolumn{2}{|c|}{$[800,900]$} & {$[0.350,0.650]$} \\
\hline Candidate 3 & {$[0.200,0.400]$} & \multicolumn{2}{|c|}{$[1000,1100]$} & {$[0.600,0.800]$} \\
\hline Candidate 4 & {$[0.600,0.800]$} & \multicolumn{2}{|c|}{$[800,1000]$} & {$[0.350,0.650]$} \\
\hline Candidate 5 & {$[0.600,0.800]$} & \multicolumn{2}{|c|}{$[700,800]$} & {$[0.200,0.400]$} \\
\hline
\end{tabular}

Applying the OCRA-G method, the final crisp scores and rankings of the candidates were obtained. Table 10 accounts for the results of the OCRA-G method.

Table 10. The results of OCRA-G.

\begin{tabular}{|c|c|c|c|c|}
\hline Alternatives & $\otimes I_{i}$ & $\otimes S_{i}$ & $\otimes O_{i}$ & $\otimes \boldsymbol{R}_{i}$ \\
\hline Candidate 1 & {$[-0.080,0.059]$} & {$[-0.139,0.139]$} & {$[0.187,1.040]$} & {$[-0.395,1.476]$} \\
\hline Candidate 2 & {$[0.040,0.118]$} & {$[-0.019,0.198]$} & {$[-0.202,0.777]$} & {$[-0.784,1.213]$} \\
\hline Candidate 3 & {$[-0.040,0.059]$} & {$[-0.099,0.139]$} & {$[0.359,1.072]$} & {$[-0.223,1.508]$} \\
\hline Candidate 4 & {$[0,0.118]$} & {$[-0.059,0.198]$} & {$[0.020,0.926]$} & {$[-0.562,1.362]$} \\
\hline Candidate 5 & {$[0.080,0.148]$} & {$[0.021,0.228]$} & {$[-0.436,0.582]$} & {$[-1.018,1.018]$} \\
\hline Alternatives & $\otimes \boldsymbol{P}_{i}$ & & & Rankings \\
\hline Candidate 1 & {$[-1.780,2.612]$} & & & 2 \\
\hline Candidate 2 & {$[-2.049,2.408]$} & & & 4 \\
\hline Candidate 3 & {$[-1.568,2.644]$} & & & 1 \\
\hline Candidate 4 & {$[-1.867,2.557]$} & & & 3 \\
\hline Candidate 5 & {$[-2.243,2.243]$} & & & 5 \\
\hline
\end{tabular}

According to the conducted case study and the proposed methodology, Candidate 3 was the best in terms of the evaluated criteria.

\section{Conclusions}

The guiding idea of this paper is the introduction of a hybrid MCDM model, which will facilitate the candidate selection process for candidates applying for a particular work position. To appreciate a changeable environment that certainly affects the decision-making process, a grey extension of the PIPRECIA method was developed by the authors of this paper for the purpose of defining criteria significance; for the final assessment and ranking of the candidates, the OCRA-G method was applied. 
The application of grey numbers allows different scenarios to be analyzed as the most unfavorable, most favorable, and realistic, which helps the decision-maker to analyze and explore different scenarios and choose the best solution. For this reason, in this paper, an extension of the PIPRECIA method based on the application of grey numbers is proposed. When it comes to the OCRA-G method, the reason for the application of the OCRA-G method is reflected in the fact that the mentioned method has not been sufficiently applied so far and its possibilities and potential have not been adequately tested. Additionally, as with the PIPRECIA-G method, the application of grey numbers in the OCRA-G method allows the decision-making process to take into account the limitations or uncertainties that accompany this process.

Therefore, the main reason the authors of the paper proposed PIPRECIA-G for defining the criteria importance, and OCRA-G for the final ranking of the candidates rests on the fact that it is very difficult to assign single-valued significance to a particular criterion or carry out a unique assessment of a certain candidate relative to the given criteria. By introducing grey numbers into the decision-making process, decision-makers are given the possibility of expressing higher and lower ratings, thus better incorporating the uncertainty and vagueness they are faced with.

Besides the mentioned benefits, there are certain limitations of the proposed model, as well. The key limitation is the fact that the model it is more difficult to apply when examining the attitudes of unprepared respondents who are not familiar with the use of grey numbers. Furthermore, there exists a particular threat of obtaining biased results, because the determination of the criteria weights are based on the opinion of decision-makers.

The proposed hybrid model was used to select the personnel for a textile factory. The obtained results are suitable and reliable and confirm the adequacy and applicability of the proposed hybrid model. Although this model has proved its usefulness in the case of personnel selection, its possibilities should be tested in other business fields as well.

Additionally, as a direction for future research, when applying the hybrid PIPRECIA-G and OCRA-G MCDM model, a larger number of decision-makers can be involved in the decision-making process. Additionally, the procedure of determining the weights of the criteria could be improved by combining the proposed PIPRECIA-G method with some objectively directed method to ensure the reliability of the obtained results. Furthermore, for more reliable evaluation and decision-making, an additional set of evaluation criteria or sub-criteria can be included in the proposed model.

Author Contributions: Conceptualization, A.U., D.K. and G.P.; methodology, D.K., D.S. and Z.T.; validation, E.K.Z.; data curation, G.P.; writing —original draft preparation, D.S. and Z.T.; writing-review and editing, A.U. and E.K.Z.; supervision, D.K. All authors have read and agreed to the published version of the manuscript.

Funding: This research received no external funding.

Conflicts of Interest: The authors declare no conflict of interest.

\section{References}

1. Camp, R.; Vielhaber, E.M.; Simonetti, L.J. Strateško Vođenje Intervjua-Kako Zaposliti Dobre Ljude; Mate: Zagreb, Croatia, 2007. (In Croatian)

2. Miller, V.D.; Gordon, M.E. Meeting the Challenges of Human Resource Management: A Communication Perspective; Routledge: New York, NY, USA, 2014.

3. Morgeson, F.P.; Campion, M.A.; Dipboye, R.L.; Hollenbeck, J.R.; Murphy, K.; Schmitt, N. Reconsidering the use of personality tests in personnel selection contexts. Pers. Psychol. 2007, 60, 683-729. [CrossRef]

4. Cook, M.; Cripps, B. Psychological Assessment in the Workplace: A Manager's Guide; John Wiley \& Sons: New York, NY, USA, 2005.

5. Rothstein, M.G.; Goffin, R.D. The use of personality measures in personnel selection: What does current research support? Hum. Resour. Manag. Rev. 2006, 16, 155-180. [CrossRef]

6. Ghorui, N.; Ghosh, A.; Algehyne, E.A.; Mondal, S.P.; Saha, A.K. AHP-TOPSIS Inspired Shopping Mall Site Selection Problem with Fuzzy Data. Mathematics 2020, 8, 1380. [CrossRef] 
7. Chatterjee, P.; Stević, Ž. A two-phase fuzzy AHP-fuzzy TOPSIS model for supplier evaluation in manufacturing environment. Oper. Res. Eng. Sci. Theory Appl. 2019, 2, 72-90. [CrossRef]

8. Sun, C.; Li, S.; Deng, Y. Determining Weights in Multi-Criteria Decision Making Based on Negation of Probability Distribution under Uncertain Environment. Mathematics 2020, 8, 191. [CrossRef]

9. Fazlollahtabar, H.; Smailbašić, A.; Stević, Ž. FUCOM method in group decision-making: Selection of forklift in a warehouse. Decis. Mak. Appl. Manag. Eng. 2019, 2, 49-65. [CrossRef]

10. Stanujkić, D.; Karabašević, D.; Smarandache, F.; Zavadskas, E.K.; Maksimović, M. An Innovative Approach to Evaluation of the Quality of Websites in the Tourism Industry: A Novel MCDM Approach Based on Bipolar Neutrosophic Numbers and the Hamming Distance. Transform. Bus. Econ. 2019, 18, 149-162.

11. Karabašević, D.; Stanujkić, D.; Zavadskas, E.; Stanimirović, P.S.; Popovic, G.; Predić, B.; Ulutaş, A. A Novel Extension of the TOPSIS Method Adapted for the Use of Single-Valued Neutrosophic Sets and Hamming Distance for E-Commerce Development Strategies Selection. Symmetry 2020, 12, 1263. [CrossRef]

12. Klehe, U.-C. Choosing How to Choose: Institutional Pressures Affecting the Adoption of Personnel Selection Procedures. Int. J. Sel. Assess. 2004, 12, 327-342. [CrossRef]

13. Robertson, I.T.; Iles, P.A.; Gratton, L.; Sharpley, D. The Impact of Personnel Selection and Assessment Methods on Candidates. Hum. Relat. 1991, 44, 963-982. [CrossRef]

14. Kelemenis, A.; Askounis, D. A new TOPSIS-based multi-criteria approach to personnel selection. Expert Syst. Appl. 2010, 37, 4999-5008. [CrossRef]

15. Baležentis, A.; Baležentis, T.; Brauers, W.K. Personnel selection based on computing with words and fuzzy MULTIMOORA. Expert Syst. Appl. 2012, 39, 7961-7967. [CrossRef]

16. Afshari, A.R.; Yusuff, R.M.; Derayatifar, A.R. Linguistic Extension of Fuzzy Integral for Group Personnel Selection Problem. Arab. J. Sci. Eng. 2013, 38, 2901-2910. [CrossRef]

17. Saaty, T.L. The Analytic Hierarchy Process: Planning, Priority Setting, Resource Allocation; McGraw-Hill: New York, NY, USA, 1980.

18. Shannon, C.E. A Mathematical Theory of Communication. Bell Syst. Tech. J. 1948, 27, 379-423. [CrossRef]

19. Krylovas, A.; Zavadskas, E.; Kosareva, N.; Dadelo, S. New KEMIRA Method for Determining Criteria Priority and Weights in Solving MCDM Problem. Int. J. Inf. Technol. Decis. Mak. 2014, 13, 1119-1133. [CrossRef]

20. Krylovas, A.; Kazimieras Zavadskas, E.; Kosareva, N. Multiple criteria decision-making KEMIRA-M method for solution of location alternatives. Econ. Res.-Ekon. Istraživanja 2016, 29, 50-65. [CrossRef]

21. Keršulienè, V.; Zavadskas, E.K.; Turskis, Z. Selection of rational dispute resolution method by applying new Step-wise Weight Assessment Ratio Analysis (SWARA). J. Bus. Econ. Manag. 2010, 11, 243-258. [CrossRef]

22. Stanujkić, D.; Zavadskas, E.K.; Karabašević, D.; Smarandache, F.; Turskis, Z. The use of Pivot Pair-wise Relative Criteria Importance Assessment method for determining weights of criteria. Rom. J. Econ. Forecast. 2017, 20, 116-133.

23. Aghdaie, M.H.; Zolfani, S.H.; Zavadskas, E.K. Decision making in machine tool selection: An integrated approach with SWARA and COPRAS-G methods. Eng. Econ. 2013, 24, 5-17. [CrossRef]

24. Ruzgys, A.; Volvačiovas, R.; Ignatavičius, Č.; Turskis, Z. Integrated evaluation of external wall insulation in residential buildings using SWARA-TODIM MCDM method. J. Civ. Eng. Manag. 2014, 20, 103-110. [CrossRef]

25. Hashemkhani Zolfani, S.H.; Bahrami, M. Investment prioritizing in high tech industries based on SWARA-COPRAS approach. Technol. Econ. Dev. Econ. 2014, 20, 534-553. [CrossRef]

26. Stanujkic, D.; Karabašević, D.; Zavadskas, E.K. A framework for the Selection of a packaging design based on the SWARA method. Inz. Ekon.-Eng. Econ. 2015, 26, 181-187. [CrossRef]

27. Karabašević, D.; Stanujkic, D.; Urosevic, S.; Popovic, G.; Maksimovic, M. An Approach to Criteria Weights Determination by Integrating the DELPHI and the Adapted SWARA Methods. Manag. J. Sustain. Bus. Manag. Solut. Emerg. Econ. 2017, 22, 15-25. [CrossRef]

28. Stanujkic, D.; Karabasevic, D.; Sava, C. An application of the PIPRECIA and WS PLP methods for evaluating website quality in hotel industry. Quaestus 2018, 12, 190-198.

29. Popovic, G.; Stanujkic, D.; Karabasevic, D.; Maksimovic, M.; Sava, C. Multiple criteria approach in the ranking of the sustainable indicators for cultural heritage sites. Quaestus 2019, 14, 165-175. 
30. Popović, G.; Mihajlović, D. An MCDM Approach to Tourism Projects Evaluation: The Upper Danube Basin Case. In Proceedings of the 3rd International Thematic Monograph-Thematic Proceedings: Modern Management Tools and Economy of Tourism Sector in Present Era, Belgrade, Serbia, 1 January 2018; pp. 129-141.

31. Stanujkić, D.; Karabašević, D.; Zavadskas, E.; Smarandache, F.; Cavallaro, F. An approach to determining customer satisfaction in traditional Serbian restaurants. Entrep. Sustain. Issues 2019, 6, 1127-1138. [CrossRef]

32. Stanujkic, D.; Karabasevic, D.; Maksimovic, M.; Popovic, G.; Brzakovic, M. Evaluation of the e-commerce development strategies. Quaestus 2019, 14, 144-152.

33. Stević, Ž.; Stjepanović, Ž.; Božičković, Z.; Das, D.K.; Stanujkić, D. Assessment of Conditions for Implementing Information Technology in a Warehouse System: A Novel Fuzzy PIPRECIA Method. Symmetry 2018, 10, 586. [CrossRef]

34. Afshari, A.; Mojahed, M.; Yusuff, R.M. Simple additive weighting approach to personnel selection problem. Int. J. Innov. Manag. Technol. 2010, 1, 511-515.

35. Stanujkic, D.; Karabasevic, D.; Zavadskas, E.K. A New Approach for Selecting Alternatives Based on the Adapted Weighted Sum and the SWARA Methods: A Case of Personnel Selection. Econ. Comput. Econ. Cybern. Stud. Res. 2017, 51, 39-56.

36. Karabasevic, D.; Zavadskas, E.K.; Stanujkic, D.; Popovic, G.; Brzakovic, M. An approach to personnel selection in the IT industry based on the EDAS method. Transform. Bus. Econ. 2018, 17, 54-65.

37. Urosevic, S.; Karabasevic, D.; Stanujkic, D.; Maksimovic, M. An approach to personnel selection in the tourism industry based on the SWARA and the WASPAS methods. Econ. Comput. Econ. Cybern. Stud. Res. 2017, 51, 75-88.

38. Kabak, M.; Burmaoglu, S.; Kazancoglu, Y. A fuzzy hybrid MCDM approach for professional selection. Expert Syst. Appl. 2012, 39, 3516-3525. [CrossRef]

39. Liu, H.; Qin, J.-T.; Mao, L.-X.; Zhang, Z. Personnel Selection Using Interval 2-Tuple Linguistic VIKOR Method. Hum. Factors Ergon. Manuf. 2014, 25, 370-384. [CrossRef]

40. Sang, X.; Liu, X.; Qin, J. An analytical solution to fuzzy TOPSIS and its application in personnel selection for knowledge-intensive enterprise. Appl. Soft Comput. 2015, 30, 190-204. [CrossRef]

41. Karabašević, D.; Zavadskas, E.K.; Turskis, Z.; Stanujkic, D. The Framework for the Selection of Personnel Based on the SWARA and ARAS Methods Under Uncertainties. Informatica 2016, 27, 49-65. [CrossRef]

42. Ji, P.; Zhang, H.-Y.; Wang, J. A projection-based TODIM method under multi-valued neutrosophic environments and its application in personnel selection. Neural Comput. Appl. 2018, 29, 221-234. [CrossRef]

43. Dahooie, J.H.; Abadi, E.B.J.; Vanaki, A.S.; Firoozfar, H.R. Competency-based IT personnel selection using a hybrid SWARA and ARAS-G methodology. Hum. Factors Ergon. Manuf. 2018, 28, 5-16. [CrossRef]

44. Parkan, C. Operational competitiveness ratings of production units. Manag. Decis. Econ. 1994, 15, $201-221$. [CrossRef]

45. Parkan, C.; Wu, M. On the equivalence of operational performance measurement and multiple attribute decision making. Int. J. Prod. Res. 1997, 35, 2963-2988. [CrossRef]

46. Wang, S. Comments on operational competitiveness rating analysis (OCRA). Eur. J. Oper. Res. 2006, 169, 329-331. [CrossRef]

47. Chatterjee, P.; Chakraborty, S. Material selection using preferential ranking methods. Mater. Des. 2012, 35, 384-393. [CrossRef]

48. Özbek, A. Efficiency analysis of foreign-capital banks in Turkey by OCRA and MOORA. Res. J. Financ. Account. 2015, 6, 21-30.

49. Issık, A.T.; Adalı, E.A. A new integrated decision making approach based on SWARA and OCRA methods for the hotel selection problem. Int. J. Adv. Oper. Manag. 2016, 8, 140-151. [CrossRef]

50. Madić, M.; Antuchevičienè, J.; Radovanović, M.; Petković, D. Determination of Manufacturing Process Conditions by Using MCDM Methods: Application in Laser Cutting. Inz. Ekon.-Eng. Econ. 2016, 27, 144-150. [CrossRef] 
51. Stanujkic, D.; Zavadskas, E.K.; Liu, S.; Karabasevic, D.; Popovic, G. Improved OCRA method based on the use of interval grey numbers. J. Grey Syst. 2017, 29, 49-60.

52. Zavadskas, E.; Turskis, Z.; Antuchevičienè, J. Selecting a Contractor by Using a Novel Method forMultiple Attribute Analysis: Weighted Aggregated SumProduct Assessment with Grey Values (WASPAS-G). Stud. Inform. Control 2015, 24, 141-150. [CrossRef] 